\title{
Mudança curricular em Odontologia: significados a partir dos sujeitos da aprendizagem
}

João Luiz Gurgel Calvet da Silveira(a)

Vera Lúcia Garcia ${ }^{(b)}$

Silveira JLGC, Garcia VL. Curricular change within dentistry: meanings according to the subjects of the learning. Interface (Botucatu). 2015; 19(52):145-58.

This study aimed to present the perceptions of curricular changes among dentistry students through the qualitative methodological approach of a case study. A total of 147 students from eight semesters participated. A qualitative research approach was used, with the focus group technique, involving eight phases of the course and addressing the main issues relating to curricular changes. Two categories were identified through content analysis: a) professional practice as care: placing value on content and dental practices in which meanings are grounded in practicing the techniques as a form of care; and b) acceptance of the Brazilian National Health System (SUS) as the learning scenario. A feeling of acceptance of the curricular changes prevailed, although the dimensions of this acceptance need to be determined and the new curriculum needs to be better understood by the subjects involved in the changes, so that it does not become a formal prescriptive document.

Keywords: Curriculum. Dentistry. Dental education.
O objetivo deste estudo é apresentar a percepção da mudança curricular por estudantes de Odontologia, por meio da abordagem metodológica qualitativa de um estudo de caso. Participaram 147 estudantes de oito semestres. Abordagem de pesquisa qualitativa, com técnica de grupo focal, envolvendo oito fases do curso, tratando dos principais temas relacionados às mudanças ocorridas no currículo. Por intermédio da análise de conteúdo, foram identificadas duas categorias de análise: a) prática profissional como assistência: valorização de conteúdos e práticas odontológicas cujo sentido se ancora na prática da técnica como assistência; b) aprovação do Sistema Único de Saúde como cenário de aprendizagem. Prevalece o sentimento de aceitação das mudanças curriculares ocorridas, embora dimensões dessa aceitação precisem ser trabalhadas e o novo currículo precise ser mais bem compreendido pelos sujeitos implicados em sua mudança para que não se torne um documento prescritivo formal.

Palavras-chave: Currículo. Odontologia. Educação em odontologia.

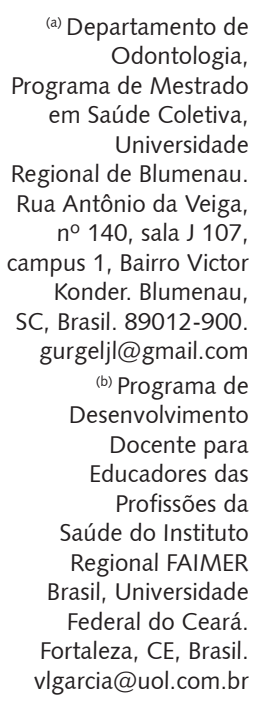

(a) Departamento de Odontologia, Programa de Mestrado em Saúde Coletiva, Universidade Regional de Blumenau. Rua Antônio da Veiga, no 140, sala J 107 , campus 1, Bairro Victor Konder. Blumenau, SC, Brasil. 89012-900. gurgeljl@gmail.com (b) Programa de Desenvolvimento Docente para Educadores das Profissões da Saúde do Instituto Regional FAIMER Brasil, Universidade Federal do Ceará. Fortaleza, CE, Brasil. vlgarcia@uol.com.br 


\section{O cenário da mudança}

A superação da formação odontológica "tradicional" - caracterizada por fragmentação de conteúdos, foco na especialização, alto custo e para a atuação quase exclusiva no mercado privado da profissão ${ }^{1}$ - constitui um desafio presente.

No âmbito das políticas públicas, destacam-se, atualmente: a implantação do Sistema Único de Saúde (SUS), com inclusão do dentista no Programa de Saúde da Famíliai i e a Política Nacional de Saúde Bucal, Brasil Sorridente ${ }^{2}$. Na educação, merece destaque a publicação das Diretrizes Curriculares Nacionais (DCNs) do curso de graduação em Odontologia ${ }^{3}$, corroborando para a formação de profissionais mais preparados para atuarem no sistema público de saúde.

Nesse contexto de mudança da formação odontológica, cabe destacar o papel relevante da Associação Brasileira de Ensino Odontológico (ABENO), subsidiando as discussões para a mudança, juntamente com segmentos da sociedade civil, da academia e de profissionais, conferindo historicidade, legalidade e legitimidade às $\mathrm{DCNs}^{4,5}$.

Um dos desafios para a implantação das DCNs pode ser identificado já no perfil proposto para o formando egresso/profissional, caracterizado por: ser generalista, humanista, crítico e reflexivo, capaz de atuar em todos os níveis de atenção com rigor técnico e científico. Capaz de resolver os problemas de saúde bucal da população, seguindo princípios éticos e legais a partir da compreensão da realidade social, cultural e econômica, visando ao benefício da sociedade ${ }^{3}$.

Nesta definição, percebe-se a manutenção da valorização da dimensão técnica e científica, ampliando, de forma considerável, a formação a partir de referenciais teórico-metodológicos das áreas das ciências humanas e sociais ou da Saúde Coletiva, pouco valorizadas nos modelos curriculares "tradicionais" da odontologia, caracterizados por: formação pela prática individual, para o mercado privado, com fragmentação de conteúdos e ensino centrado no professor especialista ${ }^{1,6}$.

Tais características desafiam as Instituições de Ensino Superior (IES), que, conforme Almeida-Filho7, caracterizam-se por predominância de faculdades tradicionais, que tendem a reagir contrariamente à pressão política conduzida pelo Estado, pressionado por movimentos sociais, em direção a modelos mais humanistas, orientados para a saúde e para o cuidado socialmente comprometido?.

Para alcançar o perfil do egresso proposto para os cursos de odontologia, são recomendadas habilidades e competências gerais definidas nas DCNs, como: 1) atenção à saúde: pensar criticamente e analisar problemas da sociedade e procurar soluções; 2 ) tomada de decisão: para o uso apropriado, eficácia e custo-efetividade dos procedimentos para a utilização de recursos, com condutas baseadas no conhecimento científico; 3) comunicação: interação com demais profissionais e com a população; 4) liderança: para atuar em equipe multiprofissional; 5) administração e gerenciamento: iniciativa e empreendedorismo nas equipes de saúde; 6) educação permanente: aprender a aprender continuamente ${ }^{3}$.

Pode-se considerar que a mudança no ensino odontológico está avançando lentamente desde a publicação das DCNs em 2002. Conforme estudo da Associação Brasileira de Ensino Odontológico 4 , envolvendo 48 escolas de Odontologia, incluindo estudantes e professores, prevalecia, entre 2005 e 2006, um estágio de "inovação incipiente" nos currículos, numa escala de cinco estágios que pode variar entre: ensino tradicional, inovação incipiente, inovação parcial, inovação avançada e transformação, considerando três "eixos" e nove "vetores" de mudança curricular, baseados no PróSaúde - Programa Nacional de Reorientação da Formação Profissional em Saúde ${ }^{8}$.

\section{O docente profissional de Odontologia}

As exigências atuais da formação odontológica ainda desafiam a Universidade e docentes para uma revisão da formação do professor, passando pela ressignificação de seu papel. Essa revisão deve ir além do ensino restrito às técnicas de uma disciplina, fruto de sua prática profissional especializada. Precisa incluir o domínio de concepções pedagógicas, novas tecnologias, abordagens e metodologias de ensino, incluindo uma visão contextualizada sobre a realidade social do país 9 . 
Entre os conhecimentos necessários ao exercício da docência, com os quais, geralmente, o professor "tradicional" de odontologia pode estar pouco familiarizado, a literatura destaca: conhecimentos pedagógicos da didática geral e dos programas institucionais; de ferramentas para docência; das dimensões subjetivas dos estudantes como sujeitos da aprendizagem; do contexto educativo e didático; dos objetivos; das finalidades e valores educativos e de seus fundamentos filosóficos e históricos ${ }^{9}$.

Como competências necessárias ao docente, são citadas: planejar; comunicação; conceber a metodologia e organizar as atividades, incluindo organização dos espaços; seleção e desenvolvimento das tarefas ${ }^{10}$. Esses conhecimentos e competências representam desafio especial no ensino das profissões da saúde, ainda hoje marcada pela valorização quase exclusiva do ensino técnico de especialidades profissionais ${ }^{11-15}$.

Outro desafio reside no fato de que a prática na área da saúde é também baseada em crenças e valores de categorias profissionais ${ }^{16}$, criando forte identidade profissional. Dessa forma, profissionais de saúde no papel de professores podem experimentar uma sensação de impotência na identificação das suas próprias falhas no exercício de seu ofício docente. Nesse contexto, valores corporativos podem representar barreiras às mudanças na educação odontológica ${ }^{16}$.

Essa situação, na IES em estudo, está sendo enfrentada por uma política de fortalecimento dos núcleos docente-estruturantes (NDE) e pelo Programa de Formação Docente (PFD), incentivando a participação dos docentes em atividades continuadas programadas a partir das demandas dos cursos, com cronogramas flexíveis e possibilitando a pontuação na carreira.

O modelo de formação em saúde predominante no Brasil ainda recebe críticas por seu distanciamento do sistema público de saúde, podendo-se constatar um considerável aumento do número de publicações sobre este tema, sobretudo nas últimas décadas ${ }^{17}$ e no exterior ${ }^{18,19}$.

Os desafios para mudança curricular dos cursos de odontologia, estabelecidos pelas $\mathrm{DCNs}^{3}$, apresentam semelhanças e especificidades com os demais cursos da saúde. Destacam-se entre estes: o despreparo no domínio de concepções pedagógicas, limitação ao domínio técnico de uma disciplina, visão descontextualizada da realidade social, fragmentação de conteúdos, desmotivação do corpo docente para a mudança, sobrecarga de trabalho em atividade de ensino, e pouco conhecimento sobre a literatura relacionada à legislação e às tendências do Ensino Superior ${ }^{9,20}$.

Essas características podem tornar difícil de sustentar uma reforma curricular ${ }^{21}$, limitando as mudanças curriculares a prescrições burocráticas e regulatórias.

Numa abordagem curricular, Freitas et al. ${ }^{12}$ enfatizam a necessidade de superação da "concepção odontocêntrica" dos currículos tradicionais de odontologia, considerando a tendência de mudança estabelecida a partir das DCNs; e apontam a necessidade de aproximação, dos estudantes, de uma "práxis da saúde coletiva", tendo os cenários do SUS um papel relevante para essa mudança.

\section{O contexto institucional da mudança curricular no caso em estudo}

O curso objeto deste estudo situa-se na região Sul, em município do interior com cerca de trezentos mil habitantes, com um dos melhores índices de desenvolvimento humano (IDH) do Brasil. Trata-se de IES pública, na qual o curso de Odontologia teve início de suas atividades no ano de 1998, sendo credenciado desde 2002. Sua trajetória é marcada por falta de consenso, resistência e pouco envolvimento dos docentes e estudantes na reforma curricular.

Em 2011, foi retomado o processo de mudança do currículo, após tentativas anteriores, para atender às exigências pedagógicas e legais.

Novos investimentos foram realizados para envolver os estudantes, informados sobre o necessário processo de mudança curricular em reuniões colegiadas, e, também, por e-mail, por meio do envio de questionários pelo Ambiente Virtual de Aprendizagem (AVA). Entretanto, a adesão ao questionário foi extremamente baixa entre os estudantes, com $22 \%$ de respondentes. Essa baixa adesão pode ser explicada pela história de insucesso das iniciativas anteriores para a mudança curricular, gerando certo descrédito, assim como pela dedicação massiva dos estudantes ao currículo integral, cuja massificação de conteúdos dificultava um maior envolvimento na vida acadêmica. 
Esse novo processo contou com a participação de estudantes representantes do Centro Acadêmico de Odontologia (CAO), e com o trabalho intenso dos seis docentes do NDE e do coordenador do curso.

Em que pesem as dificuldades relatadas, destacam-se algumas fortalezas desse processo, como o apoio institucional pela direção do Centro de Ciências da Saúde e pela Pró-Reitoria de Ensino. A participação do coordenador no "Programa de Desenvolvimento Docente para Educadores das Profissões da Saúde", promovido pela Faculdade de Medicina da Universidade Federal do Ceará, em parceria com a Foundation for Advancement of International Medical Education and Research (FAIMER), representou um importante suporte teórico-metodológico. Assim, também, como o "Programa Nacional de Reorientação da Formação Profissional em Saúde - Pró-saúde" apoiou as atividades do NDE, possibilitando a participação de convidados qualificados que contribuíram com experiências concretas de mudança curricular.

Apesar da participação limitada no âmbito do curso, o novo currículo foi aprovado por unanimidade no colegiado do curso e nas instâncias superiores da Universidade.

\section{Os sujeitos da mudança}

Pensar em mudança curricular remete a refletir sobre os sujeitos implicados. Nessa perspectiva, pensamos imediatamente: nos estudantes, nos docentes, nos usuários das clínicas, nos técnicos, na própria instituição de ensino e em outras instituições com as quais a Universidade se relaciona, além da comunidade em geral. Todos esses sujeitos, especialmente os estudantes, deveriam ser atores desse processo de mudança, portanto implicados e proativos, o que não correspondeu à realidade no caso em estudo. Por este motivo, buscamos conhecer a percepção dos estudantes de odontologia, em número de 147, representando $85 \%$ dos estudantes matriculados no curso, entendendo que a dimensão subjetiva desses sujeitos teria potencial para subsidiar e sensibilizar para a participação na avaliação permanente do currículo em implantação.

Conforme dados da Divisão de Registros Acadêmicos (DRA), o perfil dos estudantes do curso estudado pode ser caracterizado como: jovens com média de idade de 22 anos, etnia prevalentemente branca (89\%), vindos dos municípios em torno da Universidade. Em sua maioria, são estudantes exclusivos de média a alta renda familiar.

Para superar a baixa participação dos estudantes, optou-se por trabalhar com a representação por fases do curso e com representantes do CAO na primeira etapa de implantação do PPC.

\section{Percurso metodológico da pesquisa}

\section{Abordagem e desenho}

Pesquisa qualitativa caracterizada como estudo de caso, com técnica de grupo focal. Esta técnica é recomendada, em abordagem de pesquisa qualitativa, para a coleta de dados, sendo baseada no debate orientado para se atingir um melhor dimensionamento dos temas abordados ${ }^{22}$.

\section{Etapas}

1 Oficina prévia de sensibilização, com representantes dos estudantes:

Objetivo: informar sobre as mudanças aprovadas no currículo, convidar para participação nos grupos focais, e preparar ativadores para as discussões que ocorreriam nos encontros da segunda etapa, abordando as mudanças curriculares implantadas.

Metodologia: oficina única, com duração de duas horas, envolvendo estudantes do curso, sob a temática "Mudança do currículo de odontologia: o que tenho a ver com isso?".

Participantes: essa oficina foi supervisionada pelo coordenador do curso, com a presença de estudantes de cada fase - exceto da quinta fase, que não contava com turma formada por razões institucionais -, além de um representante do CAO e mais um estudante representante do Colegiado 
do Curso de Odontologia. Os estudantes representantes de oito fases, num total de 26 , foram sorteados pelo coordenador e convidados a participar.

Previamente ao encontro, foi enviada uma cópia do PPC por e-mail para todos os estudantes, com recomendação da leitura para a participação na oficina.

2 Grupos focais por fase do curso:

Objetivo: coletar dados sobre a opinião dos estudantes, por fase, a respeito da mudança.

Metodologia: técnica de grupo focal, com duração de três horas, em média, em oito grupos.

Participantes: estudantes das oito fases do curso, exceto a quinta fase, que não apresentava turma, num total de 119 estudantes e média de 14 estudantes por grupo. Os grupos foram moderados e coordenados por um dos docentes integrantes do NDE.

$\mathrm{Na}$ abertura dos grupos focais, foram apresentados os objetivos e a metodologia, seguida da leitura e assinatura do termo de consentimento livre e esclarecido (TCLE). Em seguida, foi entregue um roteiro com aspectos relevantes para o debate, contendo: a) objetivo do curso de odontologia; b) eixos principais da mudança do PPC, permitindo comparar antes e depois da mudança curricular, e c) principais aspectos das DCNs para os cursos de Odontologia.

Após os debates de cada tópico, uma síntese era elaborada por um aluno, lida para todos e aprovada pelo grupo, sendo registrada por escrito pelo relator do grupo.

A coleta de dados por meio dos grupos focais teve início no semestre seguinte à aprovação do PPC, com objetivo de divulgar e avaliar as primeiras impressões e receptividade do novo currículo.

O material coletado foi analisado a partir da técnica de análise de conteúdo ${ }^{23}$.

O projeto de pesquisa que possibilitou esta análise foi aprovado pelo Comitê de Ética na Pesquisa em Seres Humanos.

\section{Resultados}

\section{O que pensam os estudantes sobre a mudança curricular implantada}

Os resultados dos oito grupos focais foram consolidados a partir dos eixos de discussão propostos, sendo estes baseados nas propostas das DCNs, a saber:

1) Obrigatoriedade do TCC:

As DCNs explicitam em seu Art. 12: "Para a conclusão do Curso de Graduação em Odontologia, o estudante deverá elaborar um trabalho sob orientação docente" 3 (p. 71).

No contexto em estudo, o curso de odontologia não apresentava esta obrigatoriedade no currículo anterior. O entendimento do NDE é de que o curso de odontologia deve oportunizar o domínio da metodologia científica, de acordo com o pensamento predominante na formação acadêmica dos cursos de graduação, que procura integrar a pesquisa ao ensino. Dessa forma, a obrigatoriedade da apresentação do TCC não só atende a uma exigência das DCNs, como colabora para recuperar, para o curso em estudo, o seu papel acadêmico, desenvolvendo, ainda, a habilidade de se apresentar em público para a banca examinadora ${ }^{24}$.

Os estudantes, em sua maioria, reconheceram a relevância da apresentação do TCC, relacionando essa atividade com uma melhor qualificação, sobretudo visando à especialização ou à pesquisa. Competências e habilidades de comunicação, tomada de decisão, educação permanente e outras relacionadas ao processo de elaboração do TCC não foram destacadas. Revelaram preocupação com a apresentação do TCC para a banca e o tempo de dedicação necessário para realizar o TCC, conforme as falas:

\footnotetext{
"Importante para a especialização, para a formação [...] desafios: apresentar em público".

"Preocupação com o tempo para fazer o TCC".
} 
"Achamos bom, pois incentiva a pesquisa, a buscar conhecimento e também a aprender metodologia de trabalhos científicos [...]".

"Não concordamos com o TCC, mas é interessante o relato de casos executados durante o curso".

“Desafio para nós mesmos, com relação à banca, tempo, qualidade de um trabalho, um assunto e tamanho do trabalho".

"Importante, para a especialização. Deve tentar publicar. Inserir a pesquisa e tema de interesse do aluno".

2) Organização dos estágios com $20 \%$ da carga horária total:

Segundo as DCNs, a carga horária mínima de estágio curricular supervisionado deverá atingir 20\% da carga horária total do curso ${ }^{3}$.

Esse critério também está definido na legislação pertinente e no instrumento de avaliação dos cursos de bacharelado em Odontologia pelo Instituto Nacional de Estudos e Pesquisas Educacionais Anísio Teixeira (INEP) ${ }^{25,26}$.

Em que pese o fato de o currículo anterior já apresentar $20 \%$ de atividades em estágios, ainda que a carga horária das disciplinas clínicas intramuros tenha sido considerada para o credenciamento do curso, foi unânime a concordância com a ampliação dos estágios extramuros.

Estudo revela que as práticas extramuros podem contribuir, efetivamente, para o amadurecimento pessoal e profissional do estudante pelo contato real com o mundo do trabalho, possibilitando a aplicação de conhecimentos e habilidades aprendidas na universidade ${ }^{27}$.

Os estudantes demonstraram valorizar o contato com o paciente e com a realidade da profissão, conforme relatos:

“Bom, pois dá uma noção da realidade, mercado, unir o prático ao teórico, saber lidar com as pessoas, sentir a realidade".

"Ideal a carga horária, válida a inserção no SUS".

"Importante, pois na Faculdade já vem triado [o paciente], as realidades são diferentes, lá fora tem ganhos de conhecimentos".

"Necessário pela aplicação na prática, dá uma noção da realidade no SUS, pode formar opinião".

"[...] permite mais contato com o paciente, assim quando chegar nas clínicas os alunos se sentem mais seguros nos procedimentos".

3) Formação generalista:

As DCNs explicitam a necessidade da formação de um generalista, assim, também, como a instituição analisada regulamenta, para todos os cursos de graduação, a inclusão na matriz curricular de um eixo geral, um eixo específico e outro integralizador. Apesar da preferência dos estudantes por disciplinas técnicas e específicas da Odontologia, a formação generalista foi parcialmente compreendida pelos estudantes, que valorizaram a possibilidade de escolhas disponibilizada em diferentes disciplinas nos eixos citados.

Cabe destacar o desafio da formação generalista considerando que a profissão odontológica, e, consequentemente, seu ensino no modelo tradicional, ainda são fortemente marcados pelo tecnicismo e pela ênfase na especialização de profissionais, priorizando a abordagem individual, a partir da fragmentação do conhecimento ${ }^{28}$. Essas características representam um desafio para os profissionais que deverão atuar no SUS e para o perfil profissional proposto nas DCNs. 
Sobre esta temática os estudantes, com ressalvas, relataram:

"No novo currículo está melhor, o nível de exigência [de disciplinas do eixo geral] deve ser moderado, precisa entender a especificidade da área [odontologia]".

"Concordamos com o eixo geral, mas discordamos com o eixo de articulação, pois acreditamos que irá confundir o foco de cada disciplina".

"A formação não pode ser só técnica, tem que ter uma visão geral, transformação social [...] matérias optativas seria interessante".

“[...] principalmente se for disciplinas que hoje não constam em nossa grade, mais voltadas para nossa área".

"Válida, várias áreas de conhecimento e contexto social [...] mercado de trabalho".

4) Flexibilização curricular por disciplinas optativas e atividades acadêmico-científicoculturais-complementares (AACCs):

O Projeto Político Pedagógico (PPP) dos cursos de graduação é um documento institucional, para todos os cursos da instituição, que determina a inclusão de créditos obrigatórios na forma de AACCs, que podem ser escolhidas em qualquer área do conhecimento.

Os estudantes relataram valorizar a possibilidade de fazer escolhas na sua formação profissional. Entretanto, o verdadeiro objetivo das AACCs, de ampliar a formação a partir de conhecimentos e experiências de outras áreas do conhecimento na Universidade -, incluindo, aí, a dimensão humana, cultural, ética e cidadã, identificada com o conceito de profissionalismo ${ }^{29}-$, não foi identificado nos relatos, que ficaram restritos à formação acadêmica e profissional.

Seguem os relatos dos estudantes:

"Bom, pois incentiva o aluno a procurar conhecimento fora da sala de aula, a participar de palestras, bancas TCC".

"É importante para o desenvolvimento do aluno/profissional e incentiva a busca de conhecimentos".

"É válido, pois permite escolhas, ajuda a definir sua trajetória profissional".

“Válido, possibilita a participação em Pesquisa, Ensino e Extensão".

5) Redução da carga horária de conteúdos básicos:

O curso em questão apresentava a maior carga horária do Estado e uma das maiores do Brasil, ofertado de forma integral, em disciplinas, em sua grande maioria, isoladas, com muitos conteúdos básicos desconectados do ciclo profissional. Destaca-se a intenção de criar "áreas verdes" no currículo para que os estudantes tenham a oportunidade de se envolverem em atividades de pesquisa e extensão, além de favorecer o convívio no ambiente da Universidade, para além das salas de aula ou laboratórios de seu próprio curso. O NDE optou por reduzir os conteúdos básicos que eram considerados excessivos, sendo essa redução relatada, pelos estudantes, como válida, em sua maioria.

“É válido, pois não vamos lembrar tudo, havia conteúdos desnecessários".

"Aprovado, excelente, válido, pois permite focar mais a profissão e muitos conhecimentos não teriam utilidade". 
"Todos acharam ótimo, as disciplinas precisam fazer sentido".

"Importante, pois o aluno fica mais tempo no curso, focado na área [odontologia]".

6) Antecipação e ampliação das práticas laboratoriais e clínicas (superar a barreira básico/ profissional e antecipar clínicas e estágios):

A separação dos conteúdos e práticas dos ciclos básico e profissionalizante gera desmotivação e baixo rendimento, pois os estudantes não compreendem a aplicação e a importância dos conhecimentos básicos na atividade profissional. Além disso, no currículo anterior, os estudantes ingressam em disciplinas específicas apenas na quinta fase, ou seja, na segunda metade do currículo, causando desmotivação.

O tema da integração do ciclo básico com o profissional é recomendado pelo Programa Nacional de Reorientação da Formação Profissional em Saúde - Pró-Saúde ${ }^{8}$. Deve ser incluído nas propostas curriculares de forma longitudinal, a partir de modularização de conteúdos, podendo utilizar a metodologia de problematização de casos clínicos.

Foi grande a aceitação dessa mudança. Os estudantes valorizaram: a antecipação das práticas, a aproximação com o paciente, e a oportunidade de aplicarem o conhecimento aprendido, com raras ressalvas. Conforme os relatos:

"É válido, pois incentiva o aluno, adquirir mais experiência, vivência na área profissional".

"Muito válido o contato com o paciente e com a prática, melhora a decisão do aluno sobre a sua decisão profissional".

"Concordamos em parte [...] nos preocupamos em questão da teoria disso, de o curso ficar muito superficial".

"Concordamos, pois o aluno já tem um contato com o curso da área que quer cedo, saber se é o que realmente quer, e também passa mais tempo do curso focado".

"Todos acham interessante, pois estimula o aluno. Fazer a apresentação dos materiais de uso odontológico".

7) Maior carga horária com integração de clínicas. Formação do generalista:

Para superar a lógica da fragmentação dos conteúdos e práticas e fortalecer a formação do generalista, foi criada a clínica integrada, que, no currículo tradicional, está posicionada no último ano do curso, após os estudantes terem passado por diversas clínicas de especialidades ${ }^{30}$.

Essa lógica não tem cumprido o objetivo de formar generalistas, sendo necessário antecipar a integração das clínicas. No novo currículo, foi ampliada e antecipada a integração de disciplinas clínicas.

Os estudantes concordaram, em sua maioria, porém com ressalvas, pela preocupação em experienciar todos os procedimentos das disciplinas isoladas. Essa é uma percepção baseada nos currículos fortemente tradicionais, organizados em disciplinas estanques e em procedimentos específicos, embotando o cuidado integral dos sujeitos, ainda muito prevalente na Odontologia ${ }^{1}$. Seguem alguns relatos que ilustram esta visão:

"Sim importante desde que mantenha a possibilidade do aluno ver todos os procedimentos".

“Deveria ter pré-clínica [disciplina] com as disciplinas separadas e pelo menos uma clínica (semestre) separadas para dar mais segurança para os estudantes".

"É bom, pois permite uma visão mais integral do paciente". 
"Concordamos como base, mas devemos ter cada disciplina separadamente, e depois ter a junção delas".

8) Integralização do curso para cinco anos (mais um semestre em relação à matriz anterior):

Embora se possa esperar grande resistência por ampliar o tempo de curso, trata-se de exigência normativa ${ }^{31}$; entretanto, sua implantação possibilita uma maior flexibilidade curricular e o envolvimento dos estudantes em atividades de pesquisa e extensão.

A integralização do curso em cinco anos, exigência da Portaria n. 02/2007 do CONAES, seria implantada apenas para os estudantes que ingressaram na primeira fase do curso; todavia, para cumprir uma exigência da Comissão de Avaliação da Secretaria Estadual de Saúde de Santa Catarina - órgão que recredencia os cursos de graduação no Estado -, quatro fases precisaram adaptar seus currículos, incorporando a nova matriz.

Sobre a ampliação da duração do curso para cinco anos, as opiniões foram bastante divergentes, com dificuldade de consenso no grupo. Importante destacar que a maioria dos estudantes mora em municípios vizinhos, pelo caráter regional da Universidade. Seguem alguns argumentos apresentados:

"Importante [integralização em cinco anos] desde que os horários sejam bem utilizados".

"Achamos legal, sendo que continuasse em período integral".

“Cinco anos é melhor, podendo ter tempo pra participar de vários projetos, palestras, estágios em hospitais, congressos, fazendo pesquisa, etc..."

"Não há necessidade de aumento de carga horária".

"Opiniões divididas, bom, pois libera os alunos para fazer outras atividades, pesquisa, extensão, estágios, trabalhar, se deslocar".

9) Integração ensino-serviço no Sistema Único de Saúde (SUS):

A prática liberal da profissão tem sido, historicamente, o foco quase exclusivo dos currículos de odontologia do modelo tradicional no Brasil ${ }^{1,5,25}$. Essa tendência pode determinar uma certa resistência e rejeição, por parte dos alunos, das práticas no SUS.

Além disso, no meio acadêmico, os processos de mudança consolidam-se em terreno marcado pelo confronto tanto científico quanto ideológico, conforme os dizeres de Almeida-Filho ${ }^{10}$ : "O estabelecimento acadêmico, liderado por faculdades tradicionais, é contra o rearranjo da base ideológica do ensino superior e, portanto, tende a recusar modelos de cursos inovadores" (p. 7).

A formação do cirurgião-dentista, proposta nas DCNs, apresenta forte relação com o sistema público de saúde, com a necessária inserção dos estudantes nos cenários de prática do SUS.

Além de ser uma diretriz do Pró-Saúde ${ }^{8}$, estudos ${ }^{32,33}$ demonstram a importância da ampliação dos cenários de prática no SUS, com potencial para qualificar diversas dimensões do perfil profissional a ser formado no Brasil.

Em acordo com essa diretriz, foi unânime, entre os estudantes, o reconhecimento da necessidade e a valorização da experiência extramuros, especialmente no SUS, podendo ser ilustrado nos relatos:

"Prática no SUS é válida, para contato com a realidade, dá mais opção profissional".

"Somos a favor da inserção ensino-serviço no SUS em cinco fases do curso".

“Bom pelo aluno ter maior conhecimento do funcionamento do SUS, dificuldades enfrentadas nos serviços públicos, e mais interessante ainda para quem pretende seguir por essa carreira [no serviço público]". 
"É muito válido, compreensão da realidade, aplicação do conhecimento, motivação social".

"Seria ótimo [...] criando vínculo com esta inserção no SUS".

\section{Refletindo a partir das categorias de análise}

A partir das falas dos estudantes, referentes aos nove temas da mudança curricular vivenciada no curso de graduação estudado, trabalhados nas oficinas e relatados nos grupos focais, identificamse duas categorias principais de análise, sobre o significado atribuído pelos estudantes à mudança curricular.

\section{Identificação da prática profissional como assistência}

Os estudantes, em seus relatos, valorizaram os conteúdos e práticas técnicas relacionados à odontologia, assim como a possibilidade de especialização. Dessa forma, a busca de sentido para o aprendizado, segundo a maioria dos relatos, ancora-se na prática técnica, com forte valorização dos procedimentos odontológicos entendidos como assistência. O desafio é ampliar essa assistência para o conceito de atenção à saúde, entendido como atuação concomitante sobre os diferentes determinantes do processo saúde-doença bucal, cuja abrangência extrapola o âmbito da odontologia ${ }^{20}$. Esse conceito ampliado da atuação profissional está mais adequado às competências, habilidades, atitudes e ao perfil do cirurgião-dentista, sendo estabelecido nas DCNs e previsto como princípios do SUS, nas atribuições dos dentistas na Estratégia de Saúde da Família (ESF), na Política "Brasil Sorridente"2 e na Política Nacional de Atenção Básica (PNAB) ${ }^{34}$.

O desenvolvimento técnico deve responder às habilidades previstas nas DCNs, com a necessidade de se alcançar a qualificação e resolutividade da assistência clínica com a compreensão do momento político-sanitário, contemplando os princípios de avaliação dos serviços conforme o Programa de Melhoria do Acesso e da Qualidade da Atenção (PMAQ) ${ }^{35}$.

Trata-se de superar o risco de se reduzir a formação odontológica e a competência profissional à competência técnica, cuja excelência, por si só, não seria suficiente para atingir a relevância social das ações de saúde e da educação universitária, conforme o pensamento de Toassi et al. ${ }^{20}$ (p. 534): "A capacidade e habilidade técnica de tratamento de doenças não pode ser o único objetivo na formação dos profissionais de saúde". Assim, além da necessária competência técnica, a atenção em saúde bucal precisa ser integral, humanizada e compromissada com a melhoria dos indicadores de saúde bucal da população. As IES precisam formar profissionais capacitados a trazerem, para suas agendas, os determinantes sociais da saúde, tornando-se aptos a atuar em equipe, compreendendo a realidade social ${ }^{21}$.

\section{Aceitação do SUS como cenário de aprendizagem}

Tradicionalmente, o serviço público sempre foi visto de forma negativa, especialmente na formação em odontologia, supervalorizando o exercício privado. Entretanto, o significativo mercado profissional do dentista no SUS, que já é uma realidade, ainda não significa um determinante na formação, conforme relatado por Morita et al. ${ }^{4}$.

De forma adversa à tendência privativista da formação tradicional verificada na literatura ${ }^{1,5}$, podese notar, nas falas dos estudantes em estudo, uma valorização do SUS como espaço de aprendizagem, o que significa um ponto positivo a ser trabalhado para a implantação do currículo orientado pelas DCNs e um objetivo do Pró-Saúde 8 .

Estudos têm demonstrado uma melhoria da aceitação dos estudantes em atividades práticas nos cenários do SUS, identificadas com as tendências de mudança do currículo de odontologia 4,28,32,33,36. Essas experiências precisam ser conhecidas, discutidas e avaliadas para a formação de profissionais capacitados e motivados para atuar no SUS. 


\section{Em síntese}

Em muitas dimensões, no Brasil, as tendências de mudança curricular da saúde acompanham o cenário internacional, com destaque para a recomendação de currículos orientados por tendências sociais emergentes, inovações em saúde e metodologias de educação e avaliação baseadas em evidências. Recomenda-se, ainda, que as mudanças devam ser valorizadas pelos dirigentes de ensino, professores e estudantes, para que se efetivem de forma legítima ${ }^{37}$.

No presente estudo, os estudantes revelaram, de forma geral, aceitação das mudanças curriculares ocorridas no seu curso, embora algumas dimensões dessa aceitação precisem ser aprofundadas.

Confrontam-se no cenário acadêmico, além de fundamentos científicos, diferentes visões de mundo e dimensões da vida social, cujos interesses se reproduzem em argumentos mais ou menos fundamentados, porém arraigados de valores e significados que precisam ser conhecidos e debatidos à luz das tendências de mudança mais legítimas do ensino odontológico.

No âmbito institucional do curso estudado, esforços devem ser envidados para a implantação de um processo avaliativo do currículo de forma participativa, que aponte as mudanças necessárias na formação odontológica. Esse esforço deve contemplar a dimensão das necessidades profissionais dos estudantes sem se distanciar das demandas da população por uma saúde bucal digna, cujo desenvolvimento científico e tecnológico da odontologia é capaz de possibilitar nos dias atuais. Entretanto, esse benefício não será acessível ao conjunto da população se a formação desses profissionais não contemplar uma dimensão ética, politizada e identificada com os princípios do SUS, a partir das necessidades da população por saúde bucal.

Esse caminho precisa considerar as mudanças sociais e as tendências do ensino de graduação em odontologia, a partir das relevantes políticas de Estado, de forma crítica.

Em que pese o desfecho favorável no curso estudado, com a implantação do currículo aprovado nas instâncias colegiadas da instituição, vencendo as resistências à mudança e respondendo às demandas regulatórias, o novo PPC precisa ser mais bem compreendido pelos sujeitos implicados em sua mudança para que não se torne um documento prescritivo formal.

\section{Colaboradores}

João Luiz Gurgel Calvet da Silveira responsabilizou-se por elaborar o projeto, fazer a revisão de literatura, coletar os dados de pesquisa, realizar a análise dos dados e a elaboração do manuscrito. Vera Lúcia Garcia responsabilizou-se por orientar a elaboração do projeto, a revisão de literatura, a análise dos dados e participar da elaboração do manuscrito. 


\section{Referências}

1. Toassi RFC, Souza JM, Baumgarten A, Rosing CK. Avaliação curricular na educação superior em odontologia: discutindo as mudanças curriculares na formação em saúde no Brasil. Rev ABENO (Londrina). 2012; 12(2):170-7.

2. Ministério da Saúde. Política Nacional de Saúde Bucal - Brasil Sorridente [Internet]. 2004 [acesso 2014 Jul 10]. Disponível em: http://portal.saude.gov.br/portal/saude/ visualizar_texto.cfm?idtxt $=21125$

3. Almeida M. Diretrizes curriculares nacionais para os cursos universitários da área da saúde. 2a ed. Londrina: Rede Unida; 2005.

4. Morita MC, Kriger L, Carvalho ACP, Haddad AE. Implantação das Diretrizes Curriculares Nacionais em Odontologia. 2a ed. Maringá: Dental Press, Abeno, OPS, MS; 2013.

5. Silveira JLGC. Diretrizes Curriculares Nacionais para os cursos de graduação em Odontologia: historicidade, legalidade e legitimidade. Pesqui Bras Odontoped Clin Int. 2004; 4(mai/ago):151-6.

6. Ferretti LH, Appel TG, Miguel LCM, Madeira L. Avaliação discente e as Diretrizes Curriculares Nacionais: realidade das clínicas integradas da UNIVILLE. Rev ABENO. 2012; 12(2):155-62.

7. Almeida-Filho N. Ensino superior e os serviços de saúde no Brasil. The Lancet [Internet]. 2011 [acesso 2014 Jul 12]; (mai):6-7. Disponível em: http://www.abc.org.br/IMG/pdf/ doc-574.pdf

8. Ministério da Saúde. Ministério da Educação. Programa Nacional de Reorientação da Formação Profissional em Saúde - Pró-Saúde: objetivos, implementação e desenvolvimento potencial. Brasília (DF): MS; 2007.

9. Franco LLMM, Soares EF, Martorell LB, Marcelo VC. O professor do curso de Odontologia: sua formação e os desafios frente às exigências atuais. Rev Prof Docente. 2009; 9(20):57-74.

10. Shulman LS. Conocimiento y enseñanza: fundamentos de la nueva reforma. Profesorado Rev Cur Form Prof (Colombia). 2005; 9(2):1-30.

11. Zabalza MA. Competencias docentes del profesorado universitario: calidad y desarrollo profesional. Madrid: Narcea; 2006.

12. Freitas SFT, Calvo MCM, Lacerda JT. Saúde Coletiva e novas diretrizes curriculares em Odontologia: uma proposta para a graduação. Trab Educ Saude. 2012; 1(2):223-34.

13. Ceccim RB, Feuerwerker LCM. Mudança na graduação dos profissionais de saúde sobre o eixo da integralidade. Cad Saude Publica. 2004; 20(5):1400-10.

14. Carvalho ACP, Kriger L. Educação odontológica. São Paulo: Artes Médicas; 2006.

15. Papadakis MA, Paauw DS, Hafferty FW, Shapiro J, Byyny R. Perspective: the education community must develop best practices informed by evidence-based research to remediate lapses of professionalism. Acad Med. 2012; 87(12):1-5.

16. Junges R, Stello RS, Portella FF, Rosing CK, Samuel SMW. Impact of the implantation of a new curriculum in the process of learning in a Faculty of Dentistry in Brazil. Braz Oral Res. 2011; 25(6):478-84.

17. Campos FE, Aguiar RAT, Belisário SA. A formação superior dos profissionais de saúde. In: Giovanella L, Escorel S, Lobato LVC, Noronha JC, Carvalho AI, organizadores. Políticas e sistemas de saúde no Brasil. Rio de Janeiro: Fiocruz; 2008. p. 1011-34.

18. Frenk J, Bhutta ZA, Cohen J, Crisp N, Evans T, Fineberg H, et al. Health professionals for a new century: transforming education to strengthen health systems in an interdependent world. The Lancet. 2010; 376(9756):1923-58. 
19. Hackbarth G, Boccuti C. Transforming graduate medical education to improve health care value. N Engl J Med. 2011; 24:693-5.

20. Toassi RFC, Stobaus CD, Mosquera JJM, Moysés SJ. Currículo integrado no ensino de odontologia: novos sentidos para a formação na área da saúde. Interface (Botucatu). 2012; 16(4):529-42.

21. Wong TJ, Hubbal $\mathrm{H}$. Examination of curriculum reform in the four-year program of pediatric dentistry. Transf Dial Teach Learn J. 2011; 5(1):1-12.

22. Backes DS, Colomé JS, Erdmann RH, Lunardi VL. Grupo focal como técnica de coleta e análise de dados em pesquisas qualitativas. Mundo Saude. 2011; 35(4):438-42.

23. Bardin L. Análise de conteúdo. 4a ed. Lisboa: Edições 70; 2010.

24. Patrício ZM, Silvério MR, Ribeiro IM, Felisbino JE, Brodbeck IM, Martins GWM, et al. Sistematização de estratégias de ensinar-aprender pesquisa na graduação. Interface (Botucatu). 2011; 15(39):1159-72.

25. Ministério da Educação. Conselho Nacional de Educação. Câmara de Educação Superior. Resolução CNE/CES2/2007. Dispõe sobre carga horária mínima e procedimentos relativos à integralização e duração dos cursos de graduação, bacharelados, na modalidade presencial. Diário Oficial da União. 19 Jun. 2007. Seção 1:6.

26. Ministério da Educação. Instituto Nacional de Estudos e Pesquisas Educacionais Anísio Teixeira - INEP. Diretoria de Avaliação da Educação Superior - DAES. Sistema Nacional de Avaliação da Educação Superior - Sinaes. Instrumento de Avaliação de Cursos de Graduação presencial e a distância [Internet]. 2012 [acesso 2014 Jul 2]; 33. Disponível em: http://download.inep.gov.br/educacao_superior/avaliacao_cursos_graduacao/ instrumentos/2012/instrumento_com_alteracoes_maio_12.pdf

27. Souza Nétto OB, Moura MS, Lima MDM, Lages GP, Mendes RG, Moura LFAD. O PróSaúde no curso de Odontologia na Universidade Federal do Piauí (UFPI): relato de uma vivência de cinco anos. Cienc Cuid Saude. 2013; 12(2):391-7.

28. Almeida AB, Alves MS, Leite ICG. Reflexões sobre os desafios da odontologia no Sistema Único de Saúde. Rev APS. 2010; 13(1):126-32.

29. Health \& Care Professions Council. Professionalism in healthcare professional. London [Internet]. 2011 [acesso 2014 Jul 6]; 64. Disponível em: http://www.hcpc-uk.org/assets/ documents/10003771Professionalisminhealthcareprofessionals.pdf

30. Lemos CLS, Fonseca SG. Saberes e práticas curriculares: um estudo de um curso superior na área da saúde. Interface (Botucatu). 2009; 3(28):57-69.

31. Ministério da Educação. Conselho Nacional de Educação Superior. Câmara de Educação Superior. Resolução n 2, de 18 de junho de 2007 [Internet]. 2007 [acesso 2014 Jul 8]; 2. Disponível em: http://portal.mec.gov.br/cne/arquivos/pdf/2007/rces002_07.pdf

32. Alves LA, Freires IA, Braga CC, Castro RD. Experiência exitosa na atenção odontológica à comunidade. Rev Bras Cienc Saude. 2012; 16(2):235-8.

33. Albuquerque VS, Gomes AP, Rezende AHA, Sampaio MX, Dias OV, Lugarinho RM. A integração ensino-serviço no contexto dos processos de mudança na formação superior dos profissionais da Saúde. Rev Bras Educ Med. 2008; 32(3):356-62.

34. Ministério da Saúde. Secretaria de Atenção à Saúde. Departamento de Atenção Básica. Política Nacional de Atenção Básica. Brasília (DF): MS; 2012.

35. Ministério da Saúde. Secretaria de Atenção à Saúde. Departamento de Atenção Básica. Programa de Melhoria do Acesso e da Qualidade da Atenção (PMAQ). [Internet]. Brasília (DF): Ministério da Saúde; 2014 [acesso 2014 Jul 9]. Disponível em: http://dab.saude. gov.br/sistemas/pmaq/faq.php 
36. Morita MC, Kriger L. Mudanças nos cursos de odontologia e a interação com o SUS. Rev ABENO. 2004; 4(1):17-21.

37. Mcleod P, Steinert Y. Twelve tips for curriculum renewal. Med Teacher [Internet]. 2014 [acesso 2014 Jul 12]. Disponível em: http://informahealthcare.com/doi/abs/10.3109/014 2159X.2014.932898

Silveira JLGC, Garcia VL. Cambio curricular en odontología: significados a partir de los sujetos del aprendizaje. Interface (Botucatu). 2015; 19(52):145-58.

El objetivo de este estudio es presentar la percepción del cambio curricular por parte de estudiantes de odontología, por medio del abordaje metodológico cualitativo de un estudio de caso. Participaron 147 alumnos de ocho semestres. Abordaje de investigación cualitativa, con técnica de grupo focal, envolviendo ocho fases del curso, abordando los principales temas relacionados con los cambios habidos en el currículo. Por medio del análisis de contenido se identificaron dos categorías de análisis: a) práctica profesional como asistencia: valorización de contenidos y prácticas odontológicas, cuyo sentido está anclado en la práctica de la técnica como asistencia; b) aprobación del Sistema Único de Salud como escenario de aprendizaje. Prevalece el sentimiento de aceptación de los cambios curriculares habidos, aunque haya que trabajar las dimensiones de esa aceptación y el nuevo currículo tenga que ser mejor comprendido por los sujetos implicados en su cambio, para que no se convierta en un documento prescriptivo formal.

Palabras clave: Currículo. Odontología. Educación en odontología. 